\title{
The Exploration of a Technical Model for Toy Factories in China to Deal with European and US Toy Safety Requirements
}

\author{
C. W. Kwong \\ S. L. Mak \\ C. H. Li \\ School of Science and Technology \\ The Open University of Hong Kong \\ Ho Man Tin, Kowloon \\ Hong Kong SAR \\ China
}

\begin{abstract}
It is important that factories can produce safe toys and keep their business to run in an effective way. A technical model for small and medium sized toy factories in China to deal with European and US toy safety requirements has been proposed after literature survey. The technical model was proposed by considering Toy Safety Assessment; Web based product compliance platforms; the Quality Management System ISO 9001:2015; Cost and resources optimization, the Compliance Management Systems - Guidelines ISO 19600:2014 and Industry 4.0. The factory quality management system based on ISO 9001:2015 is the mediator of this model. Four factories have been selected to evaluate this model. Also, an internet questionnaire survey has been performed to evaluate the constructs of this model. It is found that all the feedbacks from the 4 factories and the findings from the internet questionnaire survey supported the model and the relationships among the constructs.
\end{abstract}

Keywords: Quality, Risk Assessment, Toy Safety, Compliance, Management System

\section{Introduction}

Nowadays, toys retailers are dominating the market, and so they give very tough offer to their suppliers, e.g., price, safety and reliability requirements, shipment window, penalty terms, etc. This makes small and medium sized toy factories having limited resources to deal with quality aspects. Most small and medium sized toys factories have difficulties to deal with worldwide toy safety requirements, so affecting their business sustainability. This is also related to Technical Barriers to Trade (TBT). It is important that factories can produce safe toys and keep their business to run in an effective way. Small and medium size factories in China employs 20 to 1000 employees(Yuan, 2014).

For the topic of Technical Barriers to Trade (TBT), the existing research thesis and journal articles are mainly written by researchers or writers with business or economic background. There is a lack of article which provides solutions on the technical side in detail which small and medium sized toy factories in China can follow and implement.

From the data of China Customs in 2016, China is the largest export country of toys, about $76 \%$ of children's toys in the world were made in China(Fan Z., Ye J. W., Zang X. J., 2017). For the toy manufacturing enterprises in China, more than $85 \%$ are exporting enterprises. Figure 1 shows that in 2016, the United States (US) is the largest export market from China (exporting percentage 34.02\%), European Union is the second largest export market from China (exporting percentage 22.66\%). For exporting location, Guang Dong Province is the highest exporting Province $(65.32 \%)$, the second largest one is Zhe Jiang Province (17.04\%). As mentioned in this article, from the data of the China Trade Remedies Information website of the China government, the recall data of European Union, US and Canada in the first quarter of $2017,70.54 \%$ of recall were due to Mechanical and Physical Safety, $18.60 \%$ of recall were due to Chemical Safety. From the data of China Customs in 2018, the United States (US) is still the largest export market from China (exporting percentage 32.55\%), European Union is the second largest export market from China (exporting percentage 22.87\%)(Fan Z., Zang X. J., Guan S. P., Chen G. H., 2019). 
Figure 1. Major export markets of China toy products in 2016

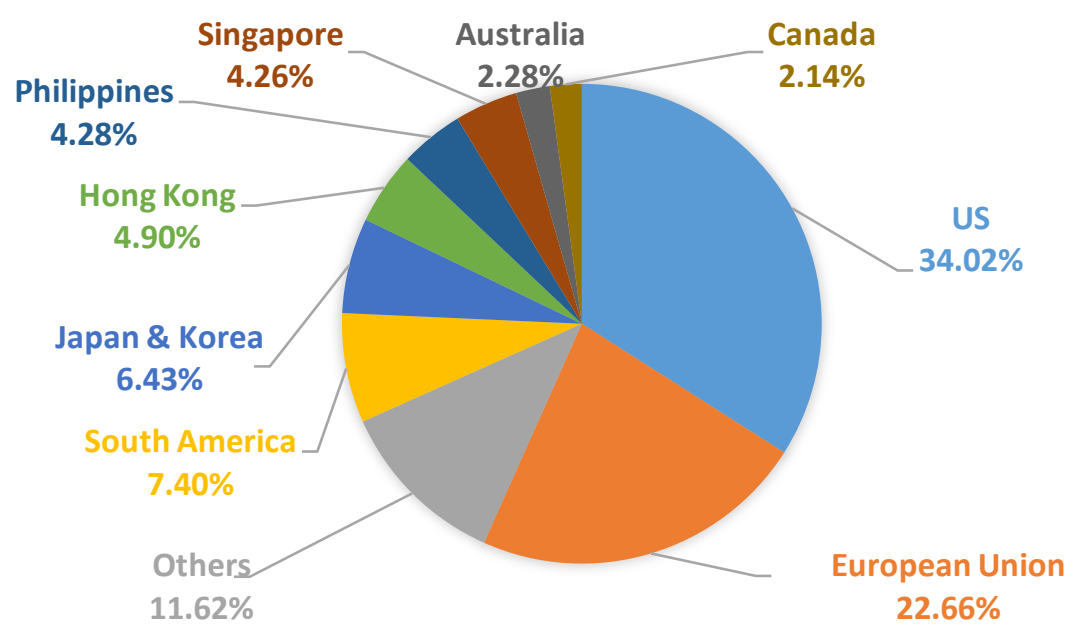

\section{Literature Review}

For the methods of toy factories in China to deal with European and US toy safety requirements, some researchers had suggested the manufacturers: (1) familiarizing with the legal and regulatory requirements of the markets; (2) diversifying the export markets; (3) diversifying the customer base; (4) developing the local China market; (5) developing own brands; and (6) making high value-added toys (Wang Z. H., 2016). Factories can expand the emerging markets to minimize the impact of Technical Barriers to Trade from European markets (Wang C. , 2015). Factories can produce innovative products by incorporating technology into products (Liu, 2014). Toys are needed to be in fusion with the entertainment industry like anime, game and movies. Also, factories need to deeply develop intelligent toy such as by using Augmented Reality (AR), Virtual Reality (VR), Application (APP), etc.(Zhang C. L., Huang Y. X., 2018). In addition, from Industry 4.0, such as Three dimensional (3D) Printing, Internet of Things (IoT) and Cyber-Physical Systems (CPS) can be adopted(Li C. H., Lau H. K., 2017). Recently, toy industry practitioners have started to use process automation and smart manufacturing (Ziyun, 2019), (Bayu_Media_Network, 2020), (EFFICIENT_TECH, 2018).

Toy Products quality and safety are the key elements in the toy manufacturing. Four main strategies are Toy Safety Assessment; Web based product compliance platforms; the Quality Management System ISO 9001:2015; Cost and resources optimization. In addition, the Compliance management systems - Guidelines ISO 19600:2014 can be a possible way to improve toy products quality and safety. Also, Industry 4.0 is a recent new strategy.

\subsection{Toy Safety Assessment}

There are different Safety Assessment Models(Mak, 2015).Toy safety assessment method can reduce product recall and can prevent a factory producing non-compliance products. For US, as required by the Consumer Product Safety Improvement Act (CPSIA) started in 2008, toys are needed to be tested to ASTM F963, Lead content and Phthalates content, etc. by a Consumer Product Safety Commission (CPSC) approved third-party laboratories. In Europe, Toy Safety Assessment is the requirement of the New Toy Safety Directive 2009/48/EC (Growth - Internal Market, Industry, Entrepreneurship and SMEs - European Commission, 2018). Toy safety assessment is the analysis of the risk of physical \& mechanical, flammability, chemical, electrical, biological, hygiene and radioactivity in toys. Toy manufacturer can refer to the European harmonized standards to demonstrate the compliance to the most requirements of New Toy Safety Directive 2009/48/EC. For Microbiological safety of toys, one can use the Recommendations and Protocols under the Directive 2009/48/EC. For chemical safety, REACH is a major regulation in Europe.

For Chemical Safety Assessment, the purpose is to evaluate chemical hazard of the product based on the review of the Bill of Materials (BOM), Bill of Substances (BOS) \& Safety Data Sheet (SDS) or Material Safety Data Sheet (MSDS), material test report, etc. The chemical risk of a product can be reduced by an effective Management System implemented in the factory and by the help of testing. In addition, in order to identify high risk materials, knowledge about the industrial use of restricted substances are essential. Besides checking with European \& US legal requirements and regulations, it is always useful to check all the information and hazard of a chemical by its CAS (Chemical Abstracts Service) number by using the internet, such as the European Chemicals Agency (ECHA) website (ECHA (European Chemicals Agency) website, 2018), so that one can identify hazardous and restriction of 
a substance, e.g., whether the substance is in the REACH SVHC list, in the Restricted Substances list of REACH Annex XVII, in the list of CMR (Carcinogenic, Mutagenic or Toxic to Reproduction) under the regulation of $1272 / 2008$ and its amendments. On the US regulatory side, one can try the website of TOXNET (TOXNET, Toxicology Data Network website, 2018). For chemical hazard evaluation, as mentioned in the article (Mak S. L., Chiu W. H., Lau H. K., 2018), manufacturers can also seek the help from certified toxicologists. It is mandatory requirements for some types of toys as mentioned in ASTM F963, such as art materials.

Major European and US toy safety requirements can be found from different laboratories websites, such as INTERTEK, BV, SGS, TÜV Rheinland and TÜV SUD. Except updated regulatory requirements, most of these laboratories also offer White Papers on their websites for visitors to download. White papers are documents helping readers to understand an issue, solve a problem, or make an informed decision. These White Papers sometimes are useful for factories to get core knowledge on a specific regulatory requirement. For example, the White Paper of Understanding California Proposition 65 (Prop 65) can be downloaded from the SGS website (SGS, 2019). In this White Paper, a quite detailed table had been used to mention different hazardous chemical limits for different product category and scope. Factories can make use of the contents in conjugate with the chemical list on the official California Proposition 65 website to perform toy safety material compliance check on their BOM and BOS. Compared with US, Europe has two special harmonized standards: EN 71-4 (Safety of toys Part 4: Experimental sets for chemistry and related activities) and EN 71-5 (Safety of toys Part 5: chemical toys (sets) other than experimental sets). If a toy factory manufactures this kind of toys and exports to Europe, the factory is required to pay special attention because EN71 has the standards from EN71-1 to EN71-14. Also, the safety standards of some countries, e.g., China or US for this kind of toys lag behind EN71-4 and EN71-5 (Yu W. J., Wei B. W., Wang X. L., 2017). In China, although has the standards of GB26387 and GB6675.13, their contents usually lag behind the most updated version of EN71-4 and EN71-5.

There are different methods to perform toy safety assessment, such as Failure Mode and Effects Analysis (FMEA), Fault Tree Analysis (FTA), Hazard and Operability Review (HAZOP), Hazard Based Safety Engineering (HBSE) (Mak, 2015). FMEA is commonly used in the toy industry. FTA is a top to down graphical failure analysis by relating the incident to a series of lower-level events. HAZOP is mainly used in the chemical industry to identify and evaluate issues that may have risks to personnel or equipment. HBSE is mainly used in electrical product industry. HBSE concerns the analysis of sources, causes and hazardous energy transfer mechanism. Elimination of hazardous energy source or preventing hazardous energy to the human body is the approach to prevent injury.

FMEA is widely used in the automotive industry because automotive components and parts need high reliability and safety requirements(Failure mode and effects analysis - Wikipedia, 2018). FMEA can be used in the toy industry because of toy safety standards, e.g., ASTM F963, EN 71, EN 62115, etc. describe a lot of failure modes. FMEA was developed in the late 1950s by reliability engineers. It is a structured and systematic technique to do failure analysis and to prevent failure. There are different types of FMEA, e.g., Design FMEA and Process FMEA. FMEA considers the Severity (S), Occurrence (O) and Detection (D) of a failure mode. FMEA can help to identify and control critical engineering parameters, the set-up of critical control points in order to lower down the possibility of failures, also can help to decide appropriate remedial measures to lower down the possibility of failures. Successful FMEA requires the analyst to include all significant failure modes and the early identification of potential failure modes. FMEA should be a living document. It is because FMEA needs to be updated when there is a change of product design, process, material, standard \& regulation, customer requirement, etc. In the mid. of 2019, a new version of FMEA was published (Chiang, 2020).

\subsection{Wed Based Product Compliance Platforms}

Performing chemical safety assessment is not an easy task because there are so many restricted and hazardous substances under quite a lot of standards and regulatory requirements. In the year 2011, Chemical Management Database was jointly developed by the company DynaSys Solutions and the Hong Kong Toy Council (CMD (Chemical Management Database) website, 2018). In the year 2013, CMD's scope was extended to Brand users, enabling the covering the entire supply chain. Chemical Management Database (CMD) is a web-based platform to help brands and factories record, manage and store BOM, BOS, SDS/MSDS, test reports, etc. Then, perform chemical safety assessment automatically by using the standards and regulatory requirements provided and updated by laboratories. For new standards and regulations, brands and factories can also receive automatic alert from the system for the presence of concerned substances or any non-compliance. This software also has many other valued functions and features as shown on its website. BOS Checker can help the copy and paste and checking of BOS in Excel format to CMD by using 100+ validation rules to ensure data format accuracy, accuracy in substance information and accuracy in concentration calculation. The Substance on Watch function can trigger alert for ingredients non-compliance in BOS. Chemical Safety Assessment function can generate Chemical Safety Assessment report for a product, so can help to meet the requirement in the New Toy Safety Directive 2009/48/EC. The advantages of CMD are minimizing compliance risk, reducing cost \& workloads, enhancing industrial collaboration throughout the supply chain. 
From an interview and conversations between the business director of the CMD in October 2019, it was found that since 2017, CMD have their own chemical team who has been working very closely with external laboratories and toys brands to keep the regulatory requirements and the substance on watch library updated. Moreover, factory audit and product inspection management function have been added. For factories, CMD Plus (CMD+) has the following key features: Manage chemical information at material and product levels; Validate material BOS; Generate product BOS; E-filing of technical documentation; Scan substance against rules\& regulations and Data alert on non-compliance.

\subsection{The Quality Management System ISO 9001:2015}

Nowadays, the most updated and worldwide recognized Quality Management System is ISO9001:2015 (ISO_QS/1, 2015). ISO9001:2015 introduces the risk-based approach into the Quality Management System (SGS, 2017). By using the risk base approach, a factory can become proactive in continual improvement and preventive action. Therefore, it is worth for a factory to make its quality management system fulfilling the ISO9001:2015 requirement. ISO 9001:2015 examines risks and opportunities in direct connection to the process in an organization. ISO 9001:2015 comprises 10 clauses. Clauses 4 to 10 form the P-D-C-A cycle (Plan - Do - Check - Act). In a guidance document of TÜV SUD, it provides practical focused interpretation of ISO 9001:2015 requirements by notes, examples of audit questions, possible process evidence, etc.(TÜV_SUD, 2017). For guidance of an organization to meet the requirements of ISO 9001:2015, one can also refer to the technical specification PD ISO/TS 9002:2016, Quality management systems - Guidelines for the application of ISO 9001:2015.

Compared with ISO 9001:2008, six clauses in ISO 9001:2015 have new concepts which are important related to toy safety assessment and product compliance as shown in Table 1.

Table 1. Six clauses in ISO 9001:2015 having new concepts which are important to toy safety assessment and product compliance

\begin{tabular}{|l|l|l|}
\hline Clause no. & Clause title & Content in brief \\
\hline 4.1 & $\begin{array}{l}\text { Understanding the organization and } \\
\text { its context }\end{array}$ & $\begin{array}{l}\text { Organization context must need to be considered } \\
\text { during the planning of the quality management } \\
\text { system. }\end{array}$ \\
\hline 5.2 & $\begin{array}{l}\text { Understanding the needs and } \\
\text { expectations of interested parties }\end{array}$ & $\begin{array}{l}\text { ISO 9001:2015 emphasizes on leadership rather than } \\
\text { just management }\end{array}$ \\
\hline 6.1 & $\begin{array}{l}\text { Actions to address risks and } \\
\text { opportunities }\end{array}$ & $\begin{array}{l}\text { The concept of preventive action is expressed through } \\
\text { by using the risk-based approach. }\end{array}$ \\
\hline 7.1 .6 & Organization knowledge & $\begin{array}{l}\text { Organization knowledge is used to ensure the } \\
\text { achieving of product conformity. }\end{array}$ \\
\hline 7.5 & Documented information & $\begin{array}{l}\text { ISO 9001:2015 has a higher flexibility on the } \\
\text { requirement on documents and records. }\end{array}$ \\
\hline
\end{tabular}

\subsection{Cost and Resources Optimization}

From the study of Zhang and Huang (2018), China has about 1800 toy manufacturing enterprises, $80 \%$ are small and medium sized or even micro enterprises, the yearly exporting amount are less than 2 million US Dollars, exporting net profit margin has been compressed to 3\% to 5\%, some enterprises even have negative profit (Zhang C. L., Huang Y. X., 2018). This article mentioned that toys are needed to be in fusion with the entertainment industry like anime, game and video, also it is needed to deeply develop intelligent toy such as by using Augmented Reality (AR), Virtual Reality (VR), Application (APP), etc. If an enterprise incorporates the factors of anime, technology like AR or VR or APP, the enterprise profit can be from $10 \%$ to $20 \%$.

"Content Creativity" and "Research \& Development" can give out high value-added toys. "Brands" and "Intellectual Property (IP)" are the core competitiveness of an enterprise (Toy_Frontier, 2017). An enterprise can take a differentiated route or specializing in a vertical field to enhance its business. An enterprise can cooperate with companies having Intellectual Property (IP). Also, an enterprise can deepen technical advantages and use technology as a core value. For Research \&Development, an enterprise can consider innovations on the directions of material, appearance and function (Ma, 2019).

The owner of IP can have high profit. Enterprise can use IP to enhance the influence of its brands (Chaoshan_merchants_network, 2018). An enterprise can initially use authorized IP to establish its business, then design and develop its own IP. Moreover, an enterprise can cooperate with an external experienced company to develop its own IP. Brands and IP are the source of value (Guang Zheng Hang Seng, 2017). An enterprise should emphases on research and development. IP can help to protect counterfeit from competitors. 
In the article, Research on the Transformation and Upgrading Mechanism Related to Blind Spot and Knowledge Search of Foundry (OEM) Enterprises in the Global Value Chain, the authors mentioned that in general, the higher the technical constitution and industrial supply chain control ability, the more value added benefit can be obtained (Shang T., Tao J. H., 2018). In the international industrial supply chain, OEM (Original Equipment Manufacturer), ODM (Original Design and Manufacturer) and OBM (Original Brand Manufacturer) occupy different knowledge zones. OEMs occupy assembly manufacturing zone. ODMs occupy design, development and assembly manufacturing zone. OBMs cover 5 knowledge zones, compared with ODMs, have extra three knowledge zones of product concept, brand promotion and sales ability. The key to the transformation and upgrading of foundry (OEM) enterprises is to transform from the knowledge zone of OEM to the knowledge zone of ODM and OBM. This involves knowledge exploitation and exploration.

Testing cost has a significant influence on the profit of an enterprise. The article, 6 Ways to Save Money on Consumer Product Testing (Without Cutting Corners) written by the laboratory STC has high reference value (STC_Group, 2018). The 6 ways are component testing, combining testing of similar items, thinking ahead by combining similar testing for different countries regulations and requirements, knowing which tests are required, not waiting to get caught, and working with a laboratory that works with you on how to save money.

Product recall is an expensive and complex task (Ahmad S., Pesch M. J., Gulati R., 2015). Recall can lead to loss of customers and damaging the image of a company. Also, it can lead to lawsuits from injuries or deaths. Therefore, a toy manufacturing enterprise needs to consider the prevention costs, appraisal cost, internal failure cost and external failure cost. Cost can be saved by decreasing rework and scrap.

Toy safety assessment can help toys factories increase their competitiveness by reducing product testing cost. For example, according to the New Toy Safety Directive explanatory guidance document, a factory can only consider actual chemical testing on the hazardous substance which is expected to be present after doing the chemical safety assessment. For another example, many buyers would like to customize factory standard products by applying slightly modification on the existing products. Toy safety assessment can be used to save testing cost.

\subsection{The Compliance Management Systems - Guidelines ISO 19600:2014}

The international standard ISO19600:2014 can be used to enhance compliance related requirements in other management systems and to improve the overall management of compliance obligations of an organization(ISO/PC_271, 2014). ISO 19600:2014 can be combined with ISO 9001 to form an integrated management system to enhance compliance related requirements management. ISO19600:2014 can help an organization maintain a culture of integrity and compliance.

ISO 19600:2014 is a standard based on the Australian standard (AS3806) compliance programs(Dowling, 2016). This article mentioned that ISO 19600 can be implemented in defensive way or offensive way depending on the company strategic approach to compliance. ISO 19600 can help a company to better allocate resources and reduce cost of non-compliance. Also, the implementation of ISO 19600 may help to mitigate any potential penalty from regulators or courts in case of non-compliance.

In ISO 19600:2014, there are several causes which is particularly helpful to improve toy products quality and safety, for examples, Compliance management system and principles of good governance (clause 4.4), Maintenance of compliance obligations (clause 4.5.2), Compliance policy (clause 5.2), Employee responsibility (clause 5.3.6), Compliance culture (clause 7.3.2.3) and Development of indicators (clause 9.1.6).

ISO 19600 is important to China factories because China enterprises sometimes have the problems of lacking effective operating and management mechanisms, and have a mentality of taking shortcuts, etc. (Wu X. J., Liang $\mathrm{H}$. L., 2016).

In 2019, ISO/TC 309 Working Group 4 (WG4) started to revise the standard ISO 19600 to a requirements standard with a new number of ISO 37301 (ISO/TC_309_WG4, 2020). Draft International Standard DIS ISO 37301 was published on 13 March 2020. ISO 37301 has adopted the "high-level structure" developed by ISO, so that it can improve the alignment and integration with ISO 9001.

\subsection{Industry 4.0}

The concept of Industry 4.0 involves Cyber Physical System (CPS), Big Data, Artificial Intelligence, Internet of Things, 3D printing, also the connecting of machines, equipment, materials, suppliers, people, products, customers, etc. (Forward_Business_Information, 2019). Intelligent manufacturing means intelligentization of management, product, machine \&equipment, production and service. The advantages of intelligent manufacturing are the increasing of efficiency, decreasing of cost, non-value-added activities, idle time of machines \& production line, defective rate, inventory and time to market.

Hong Kong Productivity Council (HKPC) is an organization in the public sector which promotes Industry 4.0. HKPC suggests that Hong Kong manufacturers should follow suit, regardless the scale of implementation(HKPC, 2018). Overseas customers also have concern about the status of Industry 4.0 in factories. For the implementation of Industry 4.0, Digitalization and Connectivity is the first step. 
For example, a factory can add sensors on existing machines to collect data. After this, the factory can create Cyber Physical System (CPS) by using real time data(HKPC, 2019). For real time data collected, data can be automatically inputted to the factory Enterprise Resource Planning (ERP) system through Internet of Things (IoT). For a toy factory with its own plastic injection molding machines, plastic injection molding process automation and Internet of Things (IoT) are important steps during the implementation of Industry 4.0. For factories making of plush toys and wooden toys, factories can start to implement Industry 4.0 by using laser cutting machines.

In the toy industry, one of the successful cases of implementing industry 4.0 is from Qman which is a plastic building blocks toy manufacturer located in Shan Tou City(Ziyun, 2019). In the past, the factory needed 1.8 people to manage one machine. After implementing industry 4.0, one person can efficiently manage 6 machines. The number of people in the injection molding workshop has been reduced from 220 to 96, but the production capacity has increased by $30 \%$.

Another successful case is from Kaigao toys (Bayu_Media_Network, 2020). Without installing of data information device, injection molding machine always needs about an hour of manual adjusting to reach the optimal state. After equipped with data information device, injection molding machine can automatically adjust to the optimal state within a few minutes after loading the mold. Also, the reaction speed is faster, the product dimension is more accurate, and the product quality is better.

From the view of factory workflow, a factory can make use of Manufacturing Execution System (MES)(EFFICIENT_TECH, 2018). MES can act as a document control centre, a data collection \& distribution centre,a real time monitoring tool of production \& quality status, etc. The using of MES is a kind of Lean Manufacturing. Using of MES is also a possibility to realize paperless factory. By using Industry 4.0, factories can increase efficiency and reduce wastage.

\section{Methodology}

After identifying the research problem and performing of literature survey, a preliminary technical model has been proposed. The technical model was delivered as a guidance document to 4 selected factories for pilot testing and subsequent longitudinal study from September 2019.

The model includes Toy Safety Assessment; Web based product compliance platforms; the Quality Management System ISO 9001:2015; Cost and resources optimization, the Compliance Management Systems - Guidelines ISO 19600:2014 and Industry 4.0. The factory quality management system based on ISO 9001:2015 is the mediator of this model. The model is called a technical model because this model is proposed mainly from the viewpoint of quality which mainly concerns technical aspects.

A questionnaire (followed up by interview), was delivered together with the technical model to get the initial answers and feedback from the 4 selected factories in September 2019. Factories started to implement the model on 1st January 2020. After implementing the model, a second questionnaire (followed up by interview), was delivered to the 4 factories to get their answers and feedback at the end of March 2020.

4 factories involve in this research project, two factories from Guang Dong Province and two factories from Zhe Jiang Province. It is because Guang Dong Province is the highest exporting Province in China and the second largest one is Zhe Jiang Province(Fan Z., Zang X. J., Guan S. P., Chen G. H., 2019).

a factory located in Zhong Shan City, Guang Dong Province which mainly making of plastic gift and premium toys with about 500 people and with ISO 9001 certification and China CCC certification

- a factory located in Shan Tou City, Guang Dong Province which mainly making of Science, Technology, Engineering, Art, Mathematics (STEAM) toys with about 100 people

a factory located in Yu Yao City, Zhe Jiang Province which mainly making of science and chemical toys, art and craft toys, with about 50 people and with ISO 9001 certification

a factory located in Ningbo City, Zhe Jiang Province which mainly making of games, plastic toys, art and craft toys with about 30 people

An internet questionnaire survey has also been performed to evaluate the importance \& weighting of the inputs of the technical model. In this survey, only Web based product compliance platforms, Compliance Management Systems - Guidelines ISO 19600:2014 and Industry 4.0 have been evaluated because Toy Safety Assessment is a regulatory requirement; Cost and resources optimization is a common strategy of many organizations.

In questionnaire design, 7 -point Likert scale has been used $(1=$ Strongly disagree, $2=$ Disagree, $3=$ Fairly disagree, $4=$ Neutral, 5 = Fairly agree, $6=$ Agree, $7=$ Strongly agree). It is because methodologists recommend 7 -point scale for a bipolar scale (SurveyMonkey, 2019). 
The internet questionnaire has been made by using the platform of wjx.cn. The internet questionnaire in Chinese has been sent out by using a convenience sampling approach to recipients in Hong Kong and in China by e-mail and instant messaging apps of WhatsApp, WeChat and QQ. By using the platform wjx.cn, duplicated filling of questionnaire by same person can be highly avoided by initial setting, limiting 1 computer or 1 mobile phone can only answer once and limiting 1 IP address can only answer once. Data collected from the internet survey have been analyzed by using the software of Minitab version 19. Data Normality have been checked. Mean, Standard Deviation and Cronbach's Alpha have been calculated.

\section{The Technical Model}

The technical model was delivered as a guidance document to factories in September 2019. A questionnaire was also delivered together at the same time to get the answers and feedback from factories.

Figure 2 shows the schematic diagram of the technical model for toy factories to deal with European and US and toy safety requirements. For each part in this schematic diagram, details and explanation were given in the guidance document.

Figure 2. Schematic diagram of the technical model for toy factories to deal with European and US and toy safety requirements

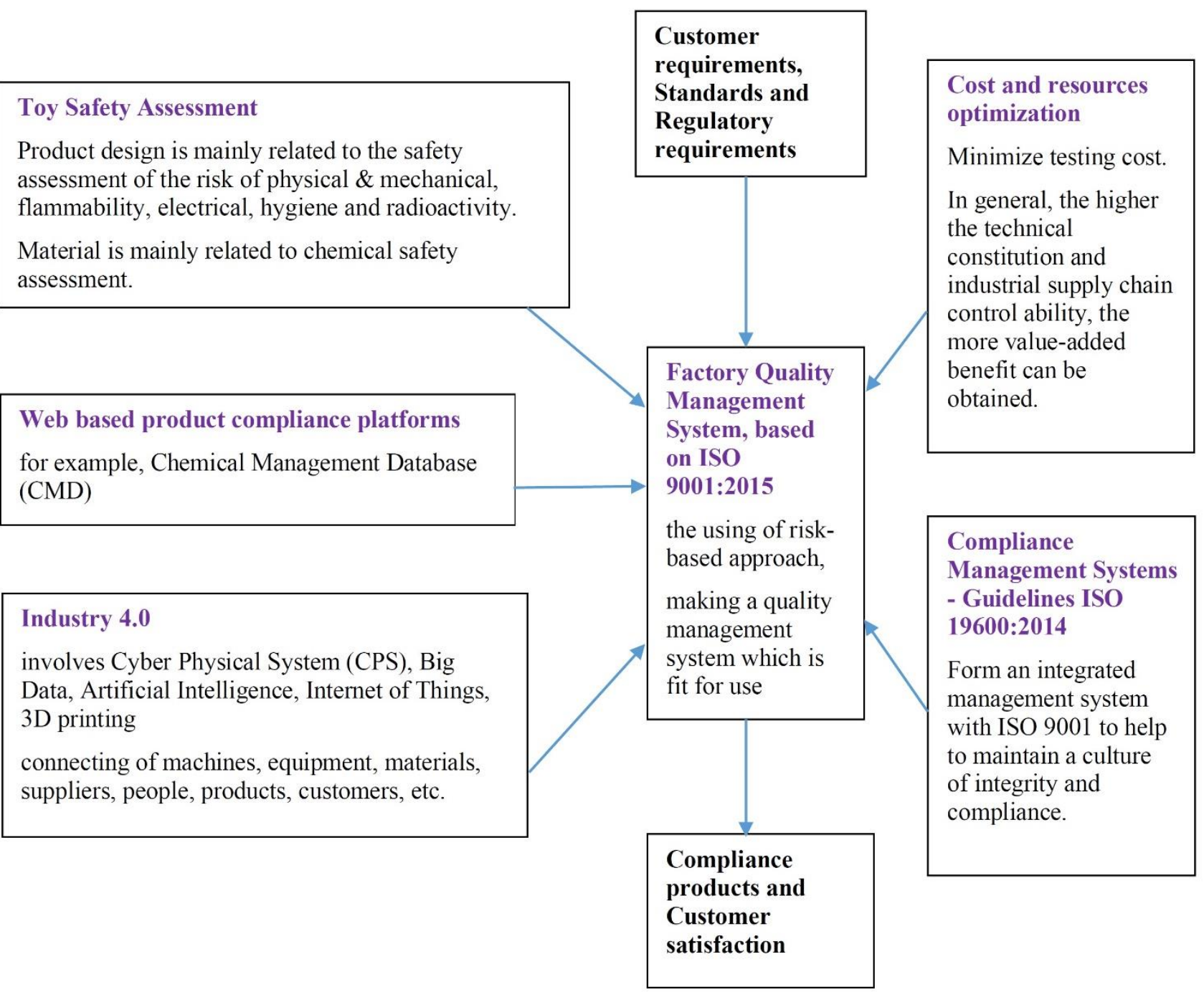

The factory quality management system based on ISO 9001:2015 is the mediator of this model. The factory quality management system serves as a mediating role in this model as shown in Table 2. 
Table 2. Inputs and outputs of the technical model

\begin{tabular}{|c|c|c|}
\hline & Input & $\begin{array}{l}\text { Output (Input to the factory Quality } \\
\text { Management System ISO 9001:2015) }\end{array}$ \\
\hline $\begin{array}{l}\text { Toy Safety } \\
\text { Assessment }\end{array}$ & $\begin{array}{lll}\text { New product } & \text { design } & \text { or product } \\
\text { change, Customer } & \text { requirements, } \\
\text { Standards } & \text { and } & \text { Regulatory } \\
\text { requirements } & & \end{array}$ & $\begin{array}{l}\text { appropriate product design and material } \\
\text { selection, } \\
\text { technical documentation and test reports }\end{array}$ \\
\hline $\begin{array}{l}\text { Web based product } \\
\text { compliance } \\
\text { platforms }\end{array}$ & $\begin{array}{l}\text { BOS, BOM, SDS / MSDS, test } \\
\text { reports, also inspection reports, audit } \\
\text { reports }\end{array}$ & $\begin{array}{l}\text { chemical safety assessment result by CMD, } \\
\text { consolidated management platform of test } \\
\text { reports, inspection reports and audit } \\
\text { reports }\end{array}$ \\
\hline $\begin{array}{l}\text { Cost and resources } \\
\text { optimization }\end{array}$ & $\begin{array}{l}\text { Increasing of testing cost due to more } \\
\& \text { more testing requirements, } \\
\text { Decreasing of profit margin due to } \\
\text { market competition }\end{array}$ & $\begin{array}{l}\text { optimized test plan and schedule, } \\
\text { business strategy which fit for the } \\
\text { company to grow }\end{array}$ \\
\hline $\begin{array}{l}\text { Compliance } \\
\text { Management } \\
\text { Systems - } \\
\text { Guidelines ISO } \\
\text { 19600:2014 } \\
\end{array}$ & $\begin{array}{l}\text { Points needed to be improved from } \\
\text { the factory management system }\end{array}$ & $\begin{array}{l}\text { Improvement plan for specific points in } \\
\text { the factory Quality Management System }\end{array}$ \\
\hline Industry 4.0 & $\begin{array}{l}\text { The concept of Digitalization and } \\
\text { Connectivity }\end{array}$ & $\begin{array}{l}\text { New process design in production, } \\
\text { New management strategy }\end{array}$ \\
\hline
\end{tabular}

There are six clauses in ISO 19600:2014 which particularly can help to improve toy products quality and safety as shown in Table 3. As mentioned in clause 9.1.6 of ISO 19600:2014, factory should develop indicators to measure the effectiveness of the management system. A factory can consider to set-up Key Performance Indicators (KPIs). This can help factories to check the effectiveness of its management system in a quantitative way. Table 3 gives out some examples of KPI.

Table 3. Six clauses in ISO 19600:2014 which particularly can help to improve toy products quality and safety

\begin{tabular}{|l|l|}
\hline Clause no. & Application \\
\hline 4.4 & Management system should reflect the organization strategy and fit for its operation. \\
\hline 4.5 .2 & $\begin{array}{l}\text { A factory should have a process to identify new and updated standards and regulations, e.g., } \\
\text { by attending seminars, by checking regulators (or laboratories) websites, etc. }\end{array}$ \\
\hline 5.2 & $\begin{array}{l}\text { Compliance policy should be supported by other documents. This can help to have a better } \\
\text { top-down approach. }\end{array}$ \\
\hline 5.3 .6 & $\begin{array}{l}\text { All employee (not just managers) should adhere to compliance responsibility which are } \\
\text { relevant to their positions and duties. }\end{array}$ \\
\hline 7.3 .2 .3 & $\begin{array}{l}\text { Factory management should treat employees as stakeholders to raise compliance culture and } \\
\text { employee responsibility on product compliance and quality. }\end{array}$ \\
\hline 9.1 .6 & $\begin{array}{l}\text { Factory should develop indicators to measure the effectiveness of the management system. A } \\
\text { factory can consider to set-up Key Performance Indicators (KPIs), such as product testing } \\
\text { passing rate of own name submissions to third party laboratories, the product testing passing } \\
\text { rate of customer submissions to third party laboratories, customer final product inspection } \\
\text { passing rate, number of non-conformities in quality related factory audit, saved testing costs, } \\
\text { etc. }\end{array}$ \\
\hline
\end{tabular}

\section{Findings from the Answers of Factories in the Initial and the Second Questionnaire}

The initial questionnaire was distributed to the factory together with a guidance document for toy factories to deal with European and US toy safety requirements in September 2019. From the answers of the 4 factories, it is found that all the 4 factories replied that no important point or factor is missing in the technical model, also they had no negative feedback or comment on this model. All the 4 factories strongly agreed that the Compliance Management Systems - Guidelines ISO 19600:2014 can help their factories improve the factory quality management system by using some content from ISO 19600 to revise the factory quality management system procedures; to establish an integrity and compliance culture; and to raise compliance responsibility of employees. All the 4 factories used Enterprise Resources Planning (ERP) system, but Industry 4.0 was not involved. 
From the answers of the 4 factories in the second questionnaire, it is found that all the 4 factories had positive feedback about the model after implementation for about 3 months.

\section{Findings from Internet Questionnaire Survey on the Inputs of the Technical Model}

An internet questionnaire survey was performed to evaluate the importance and weighting of the inputs of the technical model. The survey consisted of 19 questions. Question 1 to 4 collected the demographics information of the respondents. Question 6 to 18 assessed their views about the inputs of the technical model: Industry 4.0, Compliance Management System - Guidelines ISO 19600:2014 (GB/T 35770-2017) and Web Based Product Compliance Platform. Questions were set using a 7-point Likert scale $(1=$ Strongly disagree, $2=$ Disagree, $3=$ Fairly disagree, $4=$ Neutral, $5=$ Fairly agree, $6=$ Agree, $7=$ Strongly agree). Questions 5, 10 and 15 were screening questions to ensure that the respondents had basic understanding of Industry 4.0, Compliance Management System - Guidelines ISO 19600:2014, and had experience on Web Based Product Compliance Platform, respectively.

If a filled questionnaire cannot pass through either one of these three questions, the questionnaire is considered as unusable. The last question, Question 19, was an open-end question seeking other opinion and suggestion. Data collection started from 25th February 2020. Internet questionnaire was sent to 385 recipients in China and Hong Kong by e-mail and instant messaging apps: WhatsApp, WeChat and QQ. The survey was closed by 16th March 2020 per original 3-week schedule. After sending out the questionnaire by e-mail, a reminder e-mail was sent to recipients after a week. For questionnaires sending out by instant messaging apps, reminder messages were sent to recipients after 3 days.

Altogether, there were 89 completed questionnaires returned. Response rate was $23.1 \%$. After screening, 61 questionnaires were usable. Final response rate was $15.8 \%$.

For the 61 usable questionnaires, $45.9 \%$ of respondents located in Hong Kong, 32.8\% of respondents located in Guang Dong Province, 18.0\% of respondents located in Zhe Jiang Province and the remained 3.3\% located in Jiang Su Province. $95.1 \%$ of them had jobs related to trading or manufacturing of toys. For educational level, 50.8\% had Bachelor degree, $36.1 \%$ had Non-degree tertiary level and 8.2\% had Master degree or above. For job's type, 32.8\% worked in quality management, testing, inspection and certification, $31.2 \%$ worked in sales and merchandizing, $21.3 \%$ worked as management and $8.2 \%$ worked in engineering, research and development. For the range of age, all of them were 22 or above. $32.8 \%$ were from the age of 40 or above, $26.2 \%$ were from the age of $30-34,24.6 \%$ were from the age of 35-39.

Regarding the response on Industry 4.0, Questions 7 and 8 were set as a pair to check the internal consistency reliability. The Cronbach's Alpha of Questions 7 and 8 was 0.806. Cronbach's Alpha is about how closely related a set of items are as a group. It is a measure of scale reliability related to the number of questions concerned. The general rule is that a Cronbach's alpha of 0.70 and above is good, 0.80 and above is very good(Zhou, 2017). The result showed that the internal consistency was acceptable.

Similarly, Questions 12 and 13; Questions 16 and 17 have been set as paired to check the internal consistency reliability about ISO 19600:2014 and Web Based Product Compliance Platform respectively. The Cronbach's Alpha of Questions 12 and 13 is 0.764. The Cronbach's Alpha of Questions 16 and 17 is 0.819 . The results suggested that the internal consistency of these two constructs was satisfactory.

Table 4 shows the findings from the internet questionnaire survey on the inputs of the technical model. By considering these 6 questions, the averaged mark ranged between 5.532 to 5.875 . For $95 \%$ significance level, marks from each of these 6 questions were greater than 4. The results showed that Industry 4.0, Compliance Management System - Guidelines ISO 19600:2014 and Web Based Product Compliance Platform had a positive contribution to product safety, quality and quality management level and helped to tackle European and US toy safety requirements. The findings supported the model and the relationships among the constructs.

Table 4. Findings from the internet questionnaire survey on the inputs of the technical model

\begin{tabular}{|l|l|l|}
\hline & $\begin{array}{l}\text { Average } \\
\text { mark }\end{array}$ & $\begin{array}{l}\text { Standard } \\
\text { deviation }\end{array}$ \\
\hline Q7. Small and medium-sized toy factories should implement Industry 4.0 ? & 5.774 & 0.609 \\
\hline $\begin{array}{l}\text { Q8. Small and medium-sized toy factories can improve product safety and quality } \\
\text { through Industry 4.0? }\end{array}$ & 5.642 & 0.762 \\
\hline Q12. Small and medium-sized toy factories should implement ISO 19600:2014? & 5.708 & 0.651 \\
\hline $\begin{array}{l}\text { Q13. Small and medium-sized toy factories can improve product safety and quality } \\
\text { management level by implementing ISO 19600:2014? }\end{array}$ & 5.875 & 0.531 \\
\hline $\begin{array}{l}\text { Q16. Small and medium-sized toy factories should use web based product } \\
\text { compliance platforms? }\end{array}$ & 5.532 & 0.654 \\
\hline $\begin{array}{l}\text { Q17. Small and medium-sized toy factories can use web based product compliance } \\
\text { platforms to help to tackle European and US toy safety requirements? }\end{array}$ & 5.872 & 0.679 \\
\hline
\end{tabular}


While most respondents recognized the advantages for these inputs of the technical model, there was limited actual deployment in toy factories today. Question 9,14 and 18 attempted to explore the reasons behind. The response on Question 9 about Industry 4.0 showed that toy factories have not implemented Industry 4.0 because of cost and return issue $(98.1 \%)$ and not understanding Industry $4.0(69.8 \%)$. The response on Question 14 about ISO 19600:2014 showed that toy factories have not implemented ISO 19600:2014 because customers did not require $(83.3 \%)$ and it was not a mandatory standard or requirement $(79.2 \%)$. Also, factories did not understand ISO 19600:2014 (56.3\%). Question 18 about Web Based Product Compliance Platforms showed that toy factories have not used these platforms because the fee was not low (87.2\%) and factories did not understand web based product compliance platforms $(63.8 \%)$. These results suggested that toy industries were facing keen competition in cost. Manufacturers would not put in resources to even learn more about these tools if it was not a mandatory requirement from the system.

Apparently, not all the tactics proposed by Industry 4.0 and Compliance Management System are applicable to the toy industry. In Question 6, the respondents agreed that artificial intelligence (94.3\%), big data (92.5\%), 3D printing $(92.5 \%)$ were strongly contributed to product safety. Similarly, in question 11 , the respondents agreed that ISO 19600:2014 were strongly contributed to product safety by maintaining a culture of integrity and compliance $(93.8 \%)$ and improving compliance responsibility of employees (89.6\%).

\section{Conclusion}

In this study, the technical model has been proposed by considering Toy Safety Assessment; Web based product compliance platforms; the Quality Management System ISO 9001:2015; Cost and resources optimization, the Compliance Management Systems - Guidelines ISO 19600:2014 and Industry 4.0. The factory quality management system based on ISO 9001:2015 is the mediator of this model. 4 factories have been selected to evaluate this model. Also, an internet questionnaire survey has been performed to evaluate the constructs of this model.

It is found that feedbacks from the 4 factories and the findings from the internet questionnaire survey supported the model and the relationships among the constructs. To further evaluate this model, the longitudinal study of these 4 factories has been continued to collect data and feedback from the 4 factories after implementing the model for one year.

For toy factories, this project provides a technical model for factories to follow and implement in order to help them to deal with European and US toy safety requirements. For toy trading companies, buying office or retailers, they can also use the finding and result of this project to better manage their suppliers/factories.

\section{References}

Ahmad S., Pesch M. J., Gulati R. (2015). COST OF QUALITY: LESSONS FROM TOY RECALLS. Journal of International Business Research, 14(2), 1-14.

Bayu_Media_Network. (2020, 3 5). 涪陵高新区凯高玩具迈向工业 4.0 时代 (Kaigao toys in Fuling high tech zone march towards the era of industry 4.0). Retrieved from http://www.bycmw.com/news/newsshow147250.html

Chaoshan_merchants_network. (2018，5 17). 玩具商业模式：浅谈中小玩具企业的突围之路 (Toy Business Model: A Brief Talk on the Breakthrough of Small and Medium Toy Enterprises). Retrieved from http://mini.eastday.com/bdmip/180517214002465.html\#

Chiang, R. (2020, 1). Knowledge of the new FMEA. BSI Electronic Journal(191). Retrieved from https://www.bsigroup.com/zh-TW/e-nwsletter/

CMD (Chemical Management Database) website. (2018). Retrieved from http://www.cmd-system.com

Dowling, K. (2016, 6). Best Practice for Compliance Management: The ISO 19600 Approach. Retrieved from https://www.complianceandrisks.com/whitepaper/best-practice-compliance-management-iso-19600/

ECHA (European Chemicals Agency) website. (2018). Retrieved from https://www.echa.europa.eu

EFFICIENT_TECH. $(2018,6)$. MES 是企业解决方案的矢键要素 (MES is a key element of enterprise solutions). Retrieved from http://www.efficient.hk/jswz/info_71.aspx?itemid=580

Failure mode and effects analysis - Wikipedia. (2018). Retrieved from https://en.wikipedia.org/wiki/Failure_mode_and_effects_analysis

Fan Z., Ye J. W., Zang X. J. (2017). Study on the Influence of Technical Measures to Trade on Chinese Children's Toys Export and the Standardization Countermeasures. Standard Science(11), 137-142.

Fan Z., Zang X. J., Guan S. P., Chen G. H. (2019). Research and Countermeasures on Technical Measures to Trade of Children's Toy. China Quality and Standards Review, 7, 52-56.

Forward_Business_Information. (2019，7). 智能制造 (Intelligent Manufacturing). Retrieved from https://f.qianzhan.com/zhinengzhizao/ 
Growth - Internal Market, Industry, Entrepreneurship and SMEs - European Commission. (2018). Retrieved from http://ec.europa.eu/growth

Guang Zheng Hang Seng. (2017, 12 17).【玩具最深度】IP 视角下, 中国玩具企业的突围路径 ([The most depth of toys] IP perspective, the breakthrough path of Chinese toy companies). Retrieved from http://www.sohu.com/a/211260270_354900

HKPC. (2018). i4.0, Hong Kong manufacturers must follow suit, regardless of the scale of the implementation. Retrieved from https://www.hkpc.org/en/our-services/iiot/latest-information/i4-0-act-now

HKPC. (2019, 7). Seven Steps towards Industry 4.0 for SMEs. Retrieved from https://www.hkpc.org/en/ourservices/iiot/latest-information/7-steps-i40

ISO/PC_271. (2014). Compliance Management Systems - Guidelines, ISO 19600:2014. BSI Standards Publication.

ISO/TC_309_WG4. (2020, 1). Ongoing ISO 37301 Compliance management systems - Requirements with guidance for use. Retrieved from https://committee.iso.org/sites/tc309/home/projects/ongoing/ongoing3.html

ISO_QS/1. (2015). Quality Management Systems - Requirements, ISO 9001:2015. BSI Standards Publication.

Li C. H., Lau H. K. (2017). A Critical Review of Product Safety in Industry 4.0 Applications. 2017 IEEE International Conference on Industrial Engineering and Engineering Management (IEEM), 1661-1665.

Liu, Z. (2014). 欧盟玩具安全新指令与中国企业应对策略选择 (The new EU toy safety directive and the choice of Chinese Enterprises). Modern Business Trade Industry, 22, 49-50.

Ma, Y. (2019). Three Case Studies on Micro-Innovations. Toy Industry(6), 68-69.

Mak S. L., Chiu W. H., Lau H. K. (2018). A Critical Review of Current Safety Assessment Method of Chemical Safety in Toys. 2018 IEEE International Conference on Industrial Engineering and Engineering Management (IEEM), pp. 118-121.

Mak, S. L. (2015). An Enhanced Safety Assessment Model for Toy Products. Doctorate degree thesis in School of Science and Technology. The Open University of Hong Kong.

SGS. (2017). ISO 9001:2015 WHAT YOU NEED TO KNOW. Retrieved from https://www.sgs.com/en/whitepaper-library/iso-9001-2015-what-you-need-to-know

SGS. (2019, 6). UNDERSTANDING CALIFORNIA PROPOSITION 65 (PROP 65). Retrieved from https://www.sgs.com/en/white-paper-library/developing-effective-risk-mitigation-practices-in-response-tocalifornia-proposition-65

Shang T., Tao J. H. (2018). Research on the Transformation and Upgrading Mechanism Related to Blind Spot and Knowledge Search of Foundry Enterprises in the Global Value Chain. Science \& Technology Progress and Policy, 35(7), 141-147.

STC_Group. (2018, 5). 6 Ways to Save Money on Consumer Product Testing. Retrieved from https://www.stc.group/en/media/market-industry-info

SurveyMonkey. $(2019,11)$. What is a Likert scale? Retrieved from SurveyMonkey: https://www.surveymonkey.com/mp/likert-scale/

TOXNET, Toxicology Data Network website. (2018). Retrieved from https://toxnet.nlm.nih.gov/

Toy_Frontier. (2017, 11 17). 史上最全的玩具产业链现状分析，中小玩具商突围的黄金法则 (Most completed analysis of the status quo of the toy industry chain, the golden rule for small and medium toy manufacturers to break through). Retrieved from http://www.360doc.com/content/17/1119/10/48630098_705205347.shtml

TÜV_SUD. (2017). Quality at a glance ISO 9001:2015 Guideline. Retrieved from TUV SUD: https://www.tuvsud.com/home-com/resource-centre/publications/white-papers-e-books/iso-9001-2015-guidance

Wang, C. (2015). Research on Impacts and Measures for EU's Technical Barriers to Trade against Chinese Toy Export. Master degree thesis, Dongbei University of Finance \& Economics, China.

Wang, Z. H. (2016). The effects and solutions of TBT for China's toy export industry. Master degree thesis of Business Administration, Soo Chow University, China.

Wu X. J., Liang H. L. (2016). Discussion the Urgency of Implementing Compliance Management Systems Guidelines Standard in China. 2016 International Conference on Advanced Education and Management Engineering, 110-115.

Yu W. J., Wei B. W., Wang X. L. (2017). 中欧化学玩具安全标准差异分析及对我国化学玩具安全风险管理的 改进建议 (Difference Analysis of Safety Standards for Chemical Toys in China and Europe and Suggestions for Improvement of Safety Risk Management of Chemical Toys in China). Standard \& Quality of Light Industry(5), 9-11.

Yuan, J. (2014). Quality control of small and medium-sized foreign trade enterprises products under the influence of technical barriers to trade -- based on a case study of Ningbo Hape Toys Co. Ltd. Ningbo University. China: Master degree thesis of MBA. 
Zhang C. L., Huang Y. X. (2018). 现阶段我国玩具出口遭遇技术性贸易壁垒的特点及对策 (The characteristics and countermeasures of China's toy export encountering technical trade barriers at the present stage). China Standardization(2), 15-17.

Zhou, J. (2017). 问卷星 SPSS 问卷数据分析指南 (wjx.cn SPSS Questionnaire Data Analysis Guide). Retrieved from http://pubimage.sojump.cn/wjxspss.pdf

Ziyun. $(2019,8)$. 中国工业互联网大会开幕! 启蒙积木引领产业集群转型升级 (China Industrial Conference open! Qman building blocks lead industrial cluster transformation and upgrade). Retrieved from China Consumer Network: http://www.ccn.com.cn/html/news/xiaofeizixun/2019/0829/471981.html 